\title{
KETAATAN PENGGUNA JALAN DALAM TERTIB BERLALU LINTAS DI WILAYAH HUKUM POLRESTA DENPASAR
}

\author{
Rosalina Indah Putri, I Ketut Sukadana, Ni Made Sukaryati Karma \\ Fakultas Hukum Universitas Warmadewa, Denpasar-Bali, Indonesia
}

\begin{abstract}
Abstrak
Ketertiban dan keamana pengemudi sangatlah penting, salah satu syarat pengemudi dengan memiliki surat izin mengemudi. Pasal 281 UU LLAJ ini telah mengatur dengan jelas mengenai sanksi bagi pengendara bermotor yang tidak memiliki SIM, tentunya dengan harapan tidak ada lagi pelanggaran lalu lintas yang terjadi. Masih banyak pengendara kendaraan bermotor di wilayah hukum Polresta Denpasar yang melanggar ketentuan berkendara dengan tidak memiliki SIM. yang merupakan suatu kewajiban bagi seluruh pengendara kendaraan bermotor di jalan raya tanpa terkecual. Penelitian ini bertujuan untuk menjelskan ketaatan pengguna jalan terhadap Pasal 281 Undang-undang Nomor 22 Tahun 2009 tentang lalu lintas dan angkutan jalan dan mengungkapkan upaya kepolisian dalam mengatasi rendahnya ketaatan berlalu lintas pengguna kendaraan bermotor di wilayah hukum Kota Denpasar. Penelitian ini didesain dengan penelitian hukum empiris dengan pendekatan Perundang-undangan. Data yang digunakan yaitu bahan primer dan sekunder yang diperoleh melalui wawancara dan dokumentasi. data diolah secara kuantitatif dalam bentuk tabel dan dianalisis secara kualitatif. Ketaatan pengguna jalan terhadap Pasal 281 Undang-undang Nomor 22 Tahun 2009 tentang Lalu Lintas dan Angkutan Jalan, masih sangat kurang hal tersebut dikarenakan masih kurangnya kesadaran pengguna jalan raya, sehingga masih sangat meremehkan dan lalai dalam pembuatan surat izin mengemudi. Upaya kepolisian dalam mengatasi rendahnya ketaatan berlalu lintas pengguna kendaraan bermotor di wilayah hukum Kota Denpasar, yaitu memberikan pengenalan mengenai tertib lalu lintas sejak dini kepada anak-anak, penyuluhan dan sosialisasi terutama kepada para pelajar, mahasisawa dan pengarahan kepada warga banjar, serta penyampaian informasi tertib lalu lintas dan perkembangan situasi di jalan raya melalui media sosial.
\end{abstract}

Kata Kunci: Jalan Raya, Ketaatan Hukum, Surat Izin Mengemudi

\begin{abstract}
The order and safety of the driver is very important, one of the conditions for the driver to have a driver's license. Article 281 of the LLAJ Law clearly regulates sanctions for motorists who do not have a SIM, of course with the hope that no more traffic violations will occur. There are still many motorcyclists in the Denpasar Police jurisdiction who violate driving regulations by not having a SIM. which is an obligation for all motorists on the highway without exception. This study aims to explain the obedience of road users to Article 281 of Law Number 22 of 2009 concerning road traffic and transportation and to reveal the police's efforts to overcome the low traffic compliance of motorized vehicle users in the jurisdiction of Denpasar City. This research is designed with empirical legal research with a Legislative approach. The data used are primary and secondary materials obtained through interviews and documentation. the data is processed quantitatively in tabular form and analyzed qualitatively. Obedience of road users to Article 281 of Law Number 22 of 2009 concerning Road Traffic and Transportation, is still very lacking, this is due to the lack of awareness of road users, so they are still very dismissive and negligent in making driving licenses. Police efforts in overcoming the low traffic compliance of motorized vehicle users in the jurisdiction of Denpasar City, namely providing an introduction to traffic order from an early age to children, counseling and socialization, especially to students, students and directions to Banjar residents, as well as delivering orderly information. traffic and the development of the situation on the highway through social media.
\end{abstract}

Keywords: Highway, Law Obedience, Traffic, Driving License

\section{PENDAHULUAN}

Undang-undang Nomor 22 Tahun 2009 tentang Lalu Lintas dan Angkutan adalah peraturan yang mengatur tata tertib pengendara atau pengguna jalan di Indonesia (Alwafi Ridho Subarkah, 2018). Salah satu ketentuannya adalah dengan mewajibkan para pengendara kendaraan bermotor untuk memiliki dan membawa Surat Izin Mengemudi selama mempergunakan atau berkendaraan di jalan raya (Rifki, 2014).Salah satu syarat kepemilikan surat izin mengemudi adalah paling tidak berumur 
17 tahun dan telah lulus ujian keterampilan berkendara pada Kantor Kepolisian bidang Lalu Lintas. Beberapa tahapan ujian yang harus dilalui adalah dengan melakukan ujian berupa teori tertulis dan prakti dengan kendaraan yang disesuaikan dengan SIM yang dicari apakah SIM A untuk kendaraan roda 4 (mobil) atau SIM B kendaraan roda 2 (motor).

Syarat kepemilikan SIM adalah wajib bagi seluruh pengguna kendaraan bermotor yang mempergunakan jalan raya. Jika ada orang atau pengguna jalan yang tidak memiliki SIM maka orang tersebut dianggap tidak cakap dalam mengendarai kendaraan bermotor di jalan raya, sehingga bila diketahui melanggar akan diberikan sanksi sesuai dengan ketentuan dalam UU LLAJ berupa sanksi denda dan lainnya. Ketentuan dalam Pasal 281 UU LLAJ telah dengan jelas mengatur mengenai sanksi yang akan diberikan kepada pengguna kendaraan bermotor bila melanggar dengan tidak memiliki atau membawa SIM saat mengendarai kendaraan bermotor di jalan raya. Dengan penerapan sanksi yang tegas oleh pihak kepolisian, khususnya dari Satuan Polisi Lalu Lintas (Polantas) maka pengguna jalan akan lebih tertib dalam berkendara sehingga meminimalisir hal yang tidak diingankan. Namun, harapan tersebut rupanya belum dapat terwujud, karena data yang dimiliki oleh satuan lalu lintas Denpasar menyebutkan bahwa pelanggaran yang terjadi terus mengalami peningkatan, contohnya saja pada tahun 2018 jumlah pelanggaran lalu lintas yang terjadi di Kota Denpasar adalah 59.744 pelanggaran, sedangkan pada tahun 2019 jumlah pelanggaran meningkat menjadi 59.757 pelanggaran. Pelanggaran lalu lintas yang terjadi meliputi muatan, marka rambu, surat-surat seperti SIM dan STNK, syarat kelengkapan, dan lain sebagainya. Namun dari data tersebut jumlah pelanggaran terbanyak yaitu pelanggaran terhadap pasal 281 UU LLAJ mengenai SIM (Junef, 2014). Berdasarkan atas data yang telah diuraikan di atas maka terlihat masih ditemukannya pengendara yang melanggar ketentuan Perundang-undangan terutama pada wilayah hukum Polresta Denpasar. Bahkan pelanggaran SIM paling tinggi terjadi padahal SIM adalah suatu hal wajib yang dibawa bagi pengendara kendaraan di jalan raya. Penelitian ini bertujuan untuk menjelskan ketaatan pengguna jalan terhadap Pasal 281 Undang-undang Nomor 22 Tahun 2009 tentang lalu lintas dan angkutan jalan dan mengungkapkan upaya kepolisian dalam mengatasi rendahnya ketaatan berlalu lintas pengguna kendaraan bermotor di wilayah hukum Kota Denpasar

\section{METODE PENELITIAN}

Dalam menganalisis data penelitian ini menggunakan penilitian hukum empiris, yaitu dengan cara membandingkan antara law in the book dengan law in the action, antara teori dengan praktik, sehingga dapat ditemukan kesenjangan hukum dan diketemukan pula solusi mengatasinya (Bambang, 2002). Sumber data yang digunakan ada dua yaitu data primer yaitu data yang terdiri dari pengamatan peneliti terhadap realita yang terjadi di lapangan, seperti bahan hukum yang mempunyai kekuatan dan mengikat secara umum, sehingga berdasarkan hal tersebut peneliti dapat menganalisis fakta-fakta hukum yang terjadi (Saptomo, 2009). Sedangkan data sekunder yaitu data yang dihimpun oleh peneliti yang berasal dari peraturan Perundang-undangan, buku-buku, jurnal-jurnal dan bahan hukum cetak lainnya yang ada kaitannya dengan masalah yang sedang dikaji. Lokasi penelitian di Kantor Polisi Resor Kota (POLRESTA) Denpasar, yang berlokasi di Jl. Gunung Sanghyang No.110, Padang Sambian, Kec. Denpasar Barat, Kota Denpasar, Bali. Data diperoleh melalui teknik studi dokumen, yakni teknik yang digunakan dengan mencatat terhadap sumber bahan hukum primer dan bahan hukum sekunder yang mana selanjutkan akan ditelusuri hal-hal yang relevan dengan isu hukum yang ditulis dan teknik wawancara, yakni teknik yang dipergunakan guna mengumpulkan data berbasis wawancara dengan pihak-pihak yang relevan terhadap isu hukum yang diteliti (Soemitro, 1990). Dengan hasil wawancara tersebut penulis uraikan fakta-fakta yang terjadi di masyarakat sehingga dapat memberikan gambaran yang faktual dalam penelitian ini. Dalam mengangkat permasalahannya lebih menggunakan analisis data kualitatif yang diterapkan secara diskriptif yaitu memilih dan meringkas data yang diperoleh menjadi data lengkap yang relevan dengan permasalahannya yang mana untuk selanjutnya dianalisa.

\section{HASIL DAN PEMBAHASAN}

\section{Ketaatan Pengguna Jalan terhadap Pasal 281 Undang-undang Nomor 22 Tahun 2009 tentang Lalu Lintas dan Angkutan Jalan}

Bentuk karakteristik dari lalu lintas harus dilakukan pengembangan dan pemanfaatan yang ditujukan untuk menjangkau seluruh pelosok dan wilayah daratan yang memerlukan mobilitas tinggi dan dapat juga mengelaborasi dari sarana transportasi baik masal atau pribadi (Hariandja, 2002). Dengan 
peranan yang sangat penting dan strategis maka lalu lintas harus memenuhi standar dalam kebutuhan untuk mendukung trasnportasi sehingga tercapai lalu lintas yang selamat, tertib, nyaman, aman, cepat, lancar, teratur dan dengan biaya terjangkau oleh masyarakat umum. Pelanggaran lalu lintas merupakan tindakan atau perbuatan yang mana dilakukan seorang saat mengemudi kendaraan bermotor baik kendaraan umum atau pribadi begitu pula pejalan kaki yang melanggar ketentuan peraturan perundang-undangan yang berlaku.

Tercapainya ketertiban berlalu lintas adalah merupakan bentuk kedisiplinan seluruh insan pengguna jalan raya dan mencerminkan pula sikap dari bangsa kita sebagai bangsa yang beretika dan sopan tanpa terkecuali di jalan raya. Sebagai pengguna jalan yang baik sudah sepatutnya kita mematuhi dari pada ketentuan peraturan perundang-undangan yang berlaku. Harapannya adalah agar seluruh masyarakat mengetahui ketentuan dan etika dalam tertib berlalu lintas sesuai dengan ketentuan peraturan perundang-undangan sebagaimana dalam UU LLAJ.

Berdasarkan hasil wawancara dengan IPDA I Ketut Karta sebagai Polantas Polresta Kota Denpasar (Hasil wawancara pada hari sabtu, 7 Maret 2020, Jam 11.00 WITA), dijelaskan mengenai jenis pelanggaran yang sering dilanggar oleh para pengguna jalan di wilayah hukum Polresta Denpasar, antara lain :

a. Pengendara kendaraan bermotor tidak mempergunakan pelindung kepada tau helm saat mengendarai kendarannya di jalan raya;

b. Pengendara yang ternyata masih dibawah umur dan tidak sesuai dengan umur yang telah ditetapkan dalam UU LLAJ;

c. Banyaknya ditemukan kendaraan baik roda dua atau pun roda empat yang masih saja memuat sejumlah barang yang melebihi kapasitasnya sehingga sangat membayakan bagi dirinya sendiri dan pengendara lainnya;

d. Masih ditemukannya kendaraan bermotor khususnya roda dua yang tidak melengkapi standar kendaraan di jalan raya, antara lain tanpa spion, tanpa plat kendaraan bermotor, dan lain sebagainya;

e. Rata-rata memang pelanggaran yang dilakukan pengguna jalan adalan pelanggaran terhadap ketentuan dalam Pasal 281 dan Pasal 288 UU LLAJ.

Berdasarkan atas data dari Satlantas Polresta Denpasar mencatat khususnya mengenai pelanggaran dalam ketentuan Pasal 281 UU LLAJ mengenai tidak memiliki Surat Izin Mengemudi (SIM) pada rentang waktu 5 (lima) tahun terkahir dari 2015-2019 terus adanya peningkatan dan penurunan yang tidak signifikan, yakni :

\begin{tabular}{|l|l|l|l|l|l|}
\hline & \multicolumn{5}{|c|}{ TAHUN } \\
\cline { 2 - 6 } PELANGGARAN & 2015 & 2016 & 2017 & 2018 & 2019 \\
PASAL 281 UU & \multicolumn{5}{|c|}{ TOTAL PELANGGARAN } \\
\cline { 2 - 5 } MLAJ TIDAK & \multicolumn{5}{|c|}{} \\
\cline { 2 - 6 } & 473 & 1.174 & 1.028 & 880 & 1.648 \\
\hline
\end{tabular}

Tabel. 1 Data Pelanggaran Tidak Memiliki SIM Wilayah Hukum Polresta Denpasar

Berdasarkan data tersebut dapat dilihat adanya kenaikan pelanggaran yang terjadi dari tahun 2015 ke tahun 2016 sejumlah $40 \%$, tahun 2016 ke tahun 2017 terdapat penurunan sejumlah $12 \%$, tahun 2017 ke tahun 2018 semakin menurun sejumlah $11 \%$. Namun melonjak tajam dari tahun 2018 ke tahun 2019 sejumlah $48 \%$. Maka dapat disimpulkan bahwa penurunan paling tajam selama periode 2015-2019 pelanggaran pada tahun 2018, namun kembali melonjak dua kali lipat pada tahun 2019. Pelanggaran lalu lintas juga tercermin dari prilaku pengendara sepeda motor dijalan raya yang lebih condong mementingkan kepentingan individu pengendara dari pada keselamatannya hal ini mengakibatkan pengendara sepeda motor menjadi cenderung mengabaikan peraturan lalu lintas yang ada seperti tidak menggunakan helm standar nasional yang dapat melindungi kepala dengan penuh, 
mengendarai kendaraan seenaknya sendiri, serta minimnya sikap saling menghargai dan menghormati antar sesama pengguna jalan. Berdasarkan hasil wawancara dengan IPDA I Ketut Karta sebagai Polantas Polresta Kota Denpasar pada hari Sabtu, 7 Maret 2020, Jam 11.00 WITA menyampaikan penyebab pelanggaran adalah Faktor utama penyebab munculnya pelanggaran adalah ulah dari manusia itu sendiri. Disebabkan oleh mental dan prilaku yang tidak baik dalam berlalu lintas sehingga menjadikan sikap tersebut menjadi budaya yang dianggap bisa sehari-hari. Maka sudah seharusnya pengguna jalan raya telah matang secara mental dan etika dalam berkendara di jalan raya dan juga bagaimana interaksi antara pengguna jalan tersebut, sehingga terciptanya keamanan, keselamatan dan kelancaran lalu lintas.

\section{Upaya Kepolisian dalam Mengatasi Rendahnya Ketaatan Berlalu Lintas Pengguna Kendaraan Bermotor di Wilayah Hukum Polresta Denpasar}

Penegakan hukum yang didasarkan pada UU LLAJ adalah bagian dari golongan tindak pidana, sehingga terhadap pelanggaran yang dilakukan dalam UU LLAJ haruslah mengikuti proses penegakan hukum pidana (Jasmine, 2020). Hal tersebut tentunya melibatkan pihak-pihak selain kepolisian, antara lain dari lembaga kejaksaan, lembaga pengadilan dan lembaga pemasyarakatan sehingga diharapkan penegakan hukum ini berjalan dengan tegas dan memberikan efek jera yang cukup bagi pelanggarnya.

Berdasarkan hasil wawancara dengan IPDA I Ketut Karta sebagai Polantas Polresta Kota Denpasar pada hari Rabu, 1 Juli 2020, Jam 15.37 WITA menyampaikan kendala yang dialami dalam penegakan hukum terhadap pelanggar adalah :

1. Terbatasnya Anggaran

Terbatasnya anggaran yang ada di Satlantas Polresta Denpasar membuat pihak kepolisian satuan lalu lintas dalam membuat program kerja untuk mencegah terjadinya tindak pidana lalu lintas terbatasi, mengingat kebutuhan akan program kerja dan pembaharuan program kerja yang dibutuhkan satuan polisi lalu lintas cukup banyak untuk mengatasi masalah yang ada;

2. Kurangnya Sarana dan Prasarana

Sarana dan prasarana yang dimiliki Satlantas Polresta Denpasar kurang memadai untuk mendukung kinerja polisi untuk bekerja secara maksimal. Salah satunya adalah kurangnya alat kamera CCTV yang terpasang diwilayah hukum Polresta Denpasar, kamera tersebut berfungsi menampilkan kondisi lalu lintas dimana alat tersebut terpasang dan dapat mendukung kinerja polisi lalu lintas untuk memantau kawasan-kawasan mana yang sering ditemui terjadi tindak pidana lalu lintas oleh pengguna jalan, selain itu kurangnya sarana pos jaga lalu lintas dibeberapa daerah juga dirasa kurang untuk memantau situasi dan kondisi lalu lintas khususnya pada waktu ramai-ramainya arus kendaraan bermotor dijalan raya, yang berpotensi terjadinya tidak pidana lalu lintas hingga menyebabkan kecelakaan lalu lintas;

3. Rendahnya Tingkat Kesadaran Hukum Pengguna Jalan

Pengguna jalan dalam mengendarai kendaraan bermotornya terkadang masih saja belum paham mengenai peraturan perundang-undangan yang berlaku. Mengendarai kendaraannya sesuai dengan standar yang baik dan benar sering tidak diterapkan dengan melanggar peraturan lalu lintas yang ada, contohnya tidak membawa SIM, mengemudi secara ugal-ugalan, menaikan dan menurunkan penumpang di sembarang tempat, dan melanggar marka jalan maupun traffic light.

Berdasarkan hasil wawancara dengan IPDA I Ketut Karta sebagai Polantas Polresta Kota Denpasar (Hasil wawancara pada hari Sabtu, 7 Maret 2020, Jam 11.00 WITA), dalam menanggulangi kendala-kendala yang dialami dalam penegakan hukum dan peningkatan kesadaran bagi pengguna jalan dalam berlalu lintas, yaitu:

1. Pihak Polantas Polresta Kota Denpasar memberikan pengenalan mengenai tertib lalu lintas sejak dini kepada anak-anak dengan melakukan penyuluhan di taman kanak-kanak dengan adanya pembinaan kecil yakni Polisi Sahabat Anak (POLSANAK), mendatangi sekolah-sekolah dari sekolah dasar, sekolah menengah pertama sempai dengan sekolah menengah atas dengan membentuk Patrol Keamanan Sekolah (PKS);

2. Pihak Polantas juga selalu berusaha mengambil segala kesempatan untuk memberikan penyuluhan dan sosialisasi terutama kepada para pelajar, salah satu caranya dengan langgsung memberikan pembinaan di sekolah saat upacara dan menyampaikan informasi berkaitan tentang lalu lintas; 
3. Pendekatan yang dilakukan oleh Polantas juga dengan memberikan pengarahan kepada warga banjar dalam wilayah hukum Polresta Denpasar mengenai tertib berlalu lintas;

4. Bukan saja kepada anak-anak yang masih di bangku sekolah, penyuluhan dan sosialisasi juga ditunjukkan kepada para mahasiswa dengan cara datang langsung ke kampus dan menyampaikan mengenai tertib berlalu lintas, pentingnya penggunaan helm dan lain sebagainya, kegiatan ini juga pernah diselenggarakan di Kampus Universitas Warmadewa pada tahun 2017 lalu;

5. Upaya yang dilakukan juga tidak hanya sebatas sosialisasi secara langsung namun pula, secara tidak langsung dengan penyampaian informasi tertib lalu lintas dan perkembangan situasi di jalan raya melalui media sosial, seperti facebook, instagram dan radio.

\section{SIMPULAN DAN SARAN}

\section{Simpulan}

Berdasarkan uraian-uraian bab di atas, dapat ditarik kesimpulan bahwa Ketaatan pengguna jalan terhadap Pasal 281 Undang-undang Nomor 22 Tahun 2009 tentang Lalu Lintas dan Angkutan Jalan, masih sangat kurang. Upaya kepolisian dalam mengatasi rendahnya ketaatan berlalu lintas pengguna kendaraan bermotor di wilayah hukum Kota Denpasar, dengan cara memberikan pengenalan mengenai tertib lalu lintas sejak dini kepada anak-anak dengan melakukan penyuluhan di taman kanak-kanak dengan adanya pembinaan kecil yakni polisi sahabat anak (POLSANAK), selain itu juga memberikan pengarahan kepada warga banjar dalam wilayah hukum Polresta Denpasar mengenai tertib berlalu lintas, penyuluhan dan sosialisasi juga ditunjukkan kepada para mahasiswa dengan cara datang langsung ke kampus dan menyampaikan mengenai tertib berlalu lintas, serta penyampaian informasi tertib lalu lintas dan perkembangan situasi di jalan raya melalui media sosial, seperti facebook, instagram dan radio.

\section{Saran}

Adapunpun saran yang dapat diberikan yaitu diharapkan kepada Pihak kepolisian dalam hal ini polisi lalu lintas di Polresta Kota Denpasar, agar tetap melakukan penyuluhan dan sosialisasi bahkan jika dimungkinkan intensitas dalam sosialosasi di tingkatkan dan juga adanya tindakan tegas bagi oknumoknum kepolisian yang masih saja nakal dengan melakukan pungutan atau bahkan menerima suap dalam bertugas, selanjutnya diharapkan kepada Masyarakat sekaligus sebagai pengguna jalan juga harus memperhatikan betapa pentingnya mengenai kebiasaan tertib berlalu lintas, sehingga dapat mengurangi dan bahkan mencegah adanya pelanggaran dan bahkan kecelakaan lalu lintas, sehingga pengguna jalan dapat sampai ke tujuan dengan selamat.

\section{DAFTAR PUSTAKA}

Alwafi Ridho Subarkah. (2018). Ganti Rugi terhadap Keluarga Korban Kecelakaan Lalu Lintas yang Mengakibatkan Hilangnya Nyawa Seseorang Tanpa Menghapus atau Mengurangi Pertanggungjawaban Pidana. Jurnal Lex Crimen, 7(10), 88-94.

Bambang, W. (2002). Penelitian Hukum dalam Praktek. Jakarta: Sinar Grafika.

Hariandja. (2002). Disiplin Berlalu Lintas di Jalan Raya. Jakarta. PT. Airlangga.

Jasmine, N. C. (2020). Pertanggungjawaban Pidana Kecelakaan Lalu Lintas Karena Penggunaan Smartphone Saat Mengemudi. Indonesian Journal of Criminal Law and Criminology (IJCLC), $1(1), 33-44$.

Junef, M. (2014). Perilaku Masyarakat terhadap Operasi Bukti Pelanggaran ( Tilang ) dalam Berlalu Lintas. Jurnal Widya Yustisia, 1(1), 52-60.

Rifki, M. (2014). Tinjauan Yuridis Proses Perkara Pidana Pelanggaran Lalu Lintas. Jurnal Ilmu Hukum Legal Opinion, 2(5), 121-129.

Saptomo, A. (2009). Pokok Pokok Metodologi Penelitian Hukum Empiris Murni. Jakarta. Universitas Trisaktii.

Soemitro, R. H. (1990). Metodologi Penelitian Hukum dan Jurumetri. Jakarta. Ghalia Indonesia. 